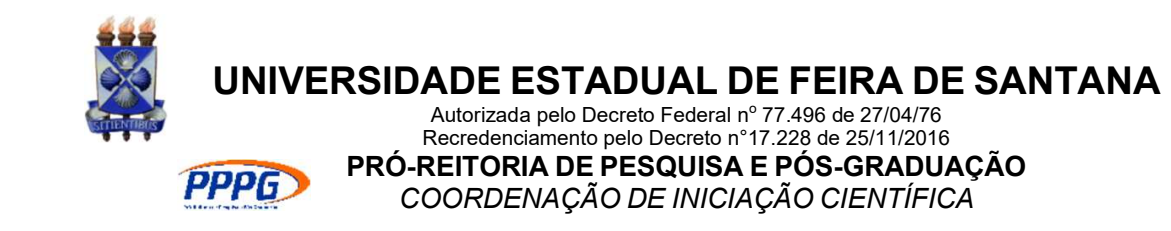

XXIII SEMINÁRIO DE INICIAÇÃO CIENTÍFICA DA UEFS

SEMANA NACIONAL DE CIENTÍFICA E TECNOLÓGICA - 2020

\title{
Atividade anticolinesterásica de espécies da família Polygalaceae: Uma revisão bibliográfica
}

\author{
Gabriel Serra Almeida'; Danielle Figuerêdo da Silva²; Clayton Queiroz Alves ${ }^{3}$; \\ Hugo Neves Brandão 4 \\ 1. Bolsista PIBIC/CNPq, Graduando em Farmácia, Universidade Estadual de Feira de Santana, e-mail: \\ gabrielunvf@gmail.com \\ 2. Participante do projeto e núcleo, Departamento de Saúde, Universidade Estadual de Feira de Santana, e-mail: \\ danielle.figs@gmail.com \\ 3. Participante do projeto e núcleo, Departamento de Exatas, Universidade Estadual de Feira de Santana, e-mail: \\ cqalves@uefs.br \\ 4. Orientador, Departamento de Saúde, Universidade Estadual de Feira de Santana, e-mail: hugo@uefs.br
}

PALAVRAS-CHAVE: Revisão; Polygalaceae; Anticolinesterasico.

\section{INTRODUÇÃO}

O surgimento das etnociências proporcionou um grande avanço na exploração científica ao longo do século XX e traz grandes resultados até a modernidade. A impulsionada procura por conhecimentos em plantas medicinais de sociedades tradicionais pode trazer a luz um conhecimento ainda não explorado, contribuindo para a percepção química e medicinal das suas biomoléculas. (GAUDÊNCIO; RODRIGUES; MARTINS, 2020).

As espécies de Polygalaceae são utilizadas tradicionalmente em todo o mundo e são grandes representantes destes espécimes pouco explorados pela ciência (GIRALDI; HANAZAKI, 2010). Com distribuição cosmopolita, elas compreendem 19 gêneros e aproximadamente 1300 espécies, tendo 11 gêneros e 199 espécies descritas no Brasil na qual 123 são endêmicas (LIMA et al. 2018).

Conhecidas principalmente pela grande quantidade de saliciato de metila no córtex de suas raízes, as espécies dessa família não estão obstantes na produção de outros metabólitos secundários, sendo encontrados na literatura a presença de cumarinas, saponinas, xantonas, ácidos graxos, alcaloides e fenóis (ROCHA, 2012).

Estas classes químicas são o principal foco da exploração cientifica e achados inéditos podem contribuir para a terapêutica de enfermidades especificas, como a doença de Alzheimer (DA). A principal estratégia terapêutica da DA é a utilização de inibidores da acetilcolinesterase, dessa forma, o objetivo do trabalho foi analisar a literatura existente para atividade anticolinesterásica de espécies de Polygalaceae.

\section{MATERIAIS E MÉTODOS}

Foi realizada uma revisão bibliográfica utilizando as bases de dado online Google Scholar e Repositório e Periódicos Capes. Foram utilizadas as palavras chave "Polygalaceae, Acetilcolinesterase, Fitoquímica", como critério de inclusão as 
publicações nos últimos dez anos (2009-2019) nos idiomas português e inglês, que faziam parte das áreas de conhecimento: Farmácia, Farmacologia, Química, Química Orgânica, Química de Produtos Naturais, Saúde e Biológicas. Foram selecionados após análise dos títulos, seguido dos resumos.

\section{RESULTADOS E DISCUSSÃO}

Entre as publicações selecionadas e avaliadas, apenas oito se encaixam nos critérios de inclusão seguindo proposta de atividade anticolinesterásica. Destas publicações selecionadas, três foram realizados pelo grupo de pesquisa do atual projeto.

A ausência de ensaios de atividade anticolinesterásica para espécies de Polygalaceae não condiz com pouca atividade para tal, ao contrário, faltam estudos para estas espécies pois, muitas das publicações citam suas capacidades neuroprotetoras, porém não testam sua ação anticolinesterásica (DUARTE et al. 2017; BEPPLER et al., 2018).

A DA é uma enfermidade neurodegenerativa que atinge principalmente os idosos e tem como principal característica a deficiência colinérgica. Esta deficiência causada pela ausência do neurotransmissor acetilcolina compromete as capacidades cognitivas, mecânicas e processos de memória e aprendizado (FALCO, 2016).

A inibição de enzimas que degradam a acetilcolina, induzindo maior tempo de ação deste neurotransmissor, é a estratégia terapêutica deste distúrbio. Todavia, o arsenal terapêutico atual não abrange respostas satisfatórias, além de ser esperado o aparecimento de efeitos adversos. Assim, a pesquisa em produtos naturais é uma das estratégias para avaliação de novos compostos eficientes e que causem menos efeitos colaterais (INOUYE; OLIVEIRA, 2004; FORLENZA, 2005).

Em estudos in vivo Xue et al. (2011) avaliou a atividade neurológica do extrato etanólico hidrolisado de Polygala tenuifolia. A atividade anticolinesterásica encontrada foi atribuída a polygalasaponinas hidrolisadas presentes no extrato, tendo atividade similar a galantamina e induzindo menor efeitos colaterais.

A Polygala tenuifolia, encontrada em prescrições chineses para tratamento neurológico, foi avaliada por Kumar et al. (2019) para atividade anticolinesterásica. A fração etanólica do extrato teve resultados significativos, com $80 \%$ de inibição enzimática, esse potencial também foi atribuído a presença de saponinas.

Foi avaliado por Venzke et al. (2015), em ensaios in vitro, os potenciais anticolinesterásicos de extratos de Polygala malluginifolia, $P$. campestres $e P$. longicaulis. A fração acetato demonstrou melhor resultados em todas as espécies, tendo inibição de $100 \%, 82 \%$ e $21 \%$. Foi atribuído superior inibição por este extrato pela presença de diidroestirilpironas.

Silva et al. (2015) aborda o estudo fitoquímico da Monnina oblongifolia evidenciando atividade inibitória da acetilcolinesterase. Utilizando os extratos bruto, etanólico, hexanico e acetato de etila demonstrou 50\%, 73,4\%, 44,2\% e 38\% de inibição, respectivamente.

A espécie Polygala boliviensis foi analisada, em teste in vitro, os extratos clorofórmico e hexânico, frações isoladas e semipurificadas para tal potencial. Do extrato clorofórmico e das substâncias aurapteno e poligaleno foi demonstrado uma inibição de 
74,22\%. 28,68\% e 51,94\%, respectivamente. O extrato hexânico não demonstrou atividade significativa em comparação com o padrão eserina, porém, ao ser fracionado, a amostra 31 demonstrou inibição significativa de 65\% (SILVA et al. 2015; SILVA et. al, 2019). Estudos por Rocha et al (2016) indicou baixa atividade para a espécie Asemeia ovata após comparação com o padrão eserina.

A fração acetato de etila do extrato de Polygala linoides avaliado por Pereira et al. (2017) demonstrou grante atividade anticolinesterásica (79,69\% de inibição). Esta atividade foi correlacionada a xantonas de propriedades intermediárias presentes no extrato.

Apesar da atividade anticolinesterásica estar mais atribuída a classes de alcaloides, existem outras classes que desempenham esse papel. Existem relações entre a produção de xantonas, saponinas, cumarinas e flavonoides e as espécies de Polygalaceae com propriedades neuroprotetoras, assim, deduz-se seu grande potencial neurológico. (MISSAU et al. 2008)

\section{CONCLUSÃO}

Trazendo em pauta a abordagem fitoquímica e quimiossistemática da família das Polygalaceae, este trabalho mostra uma potencialidade para estudos com as espécies desta família devido ao potencial neurobiológico encontrado.

O isolamento dos componentes químicos dessas espécies pouco exploradas pode contribuir para o arsenal terapêutico de doenças neurodegenerativas e melhorar a qualidade de vida de pacientes portadores de tais enfermidades.

\section{REFERÊNCIAS}

BEPPLER, Larissa May et al. Efeito do extrato hidroalcoólico da planta Polygala paniculata no modelo de fibromialgia induzido pela reserpina em camundongos: avaliação sensorial e emocional. 2018. Dissertação (Mestrado em Neurociências) Programa de Pós Graduação em Neurociências da Universidade Federal de Santa Catarina.

DUARTE, Filipe Silveira et al. Participação das dihidroestiril-2-pironas e estiril-2pironas nas ações centrais do tipo-benzodiazepínicas da planta Polygala sabulosa AW Bennett (Polygalaceae) em roedores. 2007. 154 p. Tese (Doutorado em Farmacologia) - Programa de pós graduação em Farmacologia da Universidade Federal de Santa Catarina. Disponível em:

$<$ https://repositorio.ufsc.br/bitstream/handle/123456789/90662/242398.pdf?sequence=1 $>$.

FALCO, Anna De et al. Doença de Alzheimer: hipóteses etiológicas e perspectivas de tratamento. Química Nova, v. 39, n. 1, p. 63-80, 2016.

FORLENZA, Orestes V. Tratamento farmacológico da doença de Alzheimer. Archives of Clinical Psychiatry, v. 32, n. 3, p. 137-148, 2005.

GAUDÊNCIO, Jéssica Da Silva; RODRIGUES, Sérgio Paulo Jorge; MARTINS, Décio Ruivo. Indígenas brasileiros e o uso das plantas. Khronos, n. 9, p. 20-20, 2020. 
GIRALDI, Mariana; HANAZAKI, Natalia. Uso e conhecimento tradicional de plantas medicinais no Sertão do Ribeirão, Florianópolis, SC, Brasil. Acta botanica brasilica, v. 24, n. 2, p. 395-406, 2010.

INOUYE, Keika; OLIVEIRA, G. H. de. Avaliação crítica do tratamento farmacológico atual para doença de Alzheimer. Infarma, v. 15, n. 11-12, p. 80-83, 2004.

LIMA, Igor Gonçalves et al. Flora do Ceará, Brasil: Polygalaceae. Rodriguésia, v. 69, n. 2, p. 673-692, 2018.

MISSAU, Fabiana Cristina et al. Estudo das propriedades químicas, estruturais e biológicas das espécies Polygala paniculata e Polygala pulchella. 2008. 179 p. Tese (Doutorado em Química) - Programa de Pós Graduação em Química da Universidade Federal de Santa Catarina.

PEREIRA, Marcos et al. Estudo fitoquímico e biológico de Polygala linoides. 2017. 204p. Dissertação (Mestrado em Química Orgânica) - Programa de Pós Graduação em Química da Universidade Federal de Santa Catarina.

ROCHA, José Luiz Carneiro da et al. Determinação quantitativa por CLAE-DAD de salicilato de metila e atividade antinociceptiva em espécies do gênero Polygala (Polygalaceae) ocorrentes no semiárido e cultivadas. 2012.

ROCHA, J. L. C. da. Caracterização química e atividades biológicas in vitro e in silico de Asemeia ovata (Polygalaceae). 2016. 267 p. Tese (Doutorado Acadêmico em Recursos Genéticos Vegetais)- Universidade Estadual de Feira de Santana, Feira de Santana, 2016.

SILVA, Beatriz Felix Pimenta da et al. Estudo fitoquímico e biológico de Monnina oblongifolia. 2015. 52 p. Trabalho de Conclusão de Curso.

KUMAR, Hemant et al. Traditional Korean East Asian medicines and herbal formulations for cognitive impairment. Molecules, v. 18, n. 12, p. 14670-14693, 2013. SILVA, Carol Anne Pereira. AVALIAÇÃO DAS ATIVIDADES ANTIOXIDANTE E ANTICOLINESTERÁSICA DAS FRAÇÕES DO EXTRATO HEXÂNICO DE Polygala boliviensis. Anais Seminário de Iniciação Científica, n. 22, 2019. SILVA, D.F. Estudo Fitoquímico e atividades biológicas de Polygala boliviensis A.W.; Benn (Polygaceae). 2015. 131p. Dissertação (Mestrado em Ciências Farmacêuticas) -Programa de Pós-Graduação em Ciências Farmacêuticas, Universidade Estadual de Feira de Santana.

VENZKE, Dalila et al. Estudo quimiossistemático de espécies do gênero Polygala e avaliação das propriedades biológicas. 2015. 230 p. Tese (Doutorado em química) Programa de Pós Graduação em Química da Universidade Federal de Santa Catarina. XUE, Dan et al. Cognitive-enhancing effects of polygalasaponin hydrolysate in A $\beta 25-$ 35-induced amnesic mice. Evidence-Based Complementary and Alternative Medicine, v. 2011, 2011. 